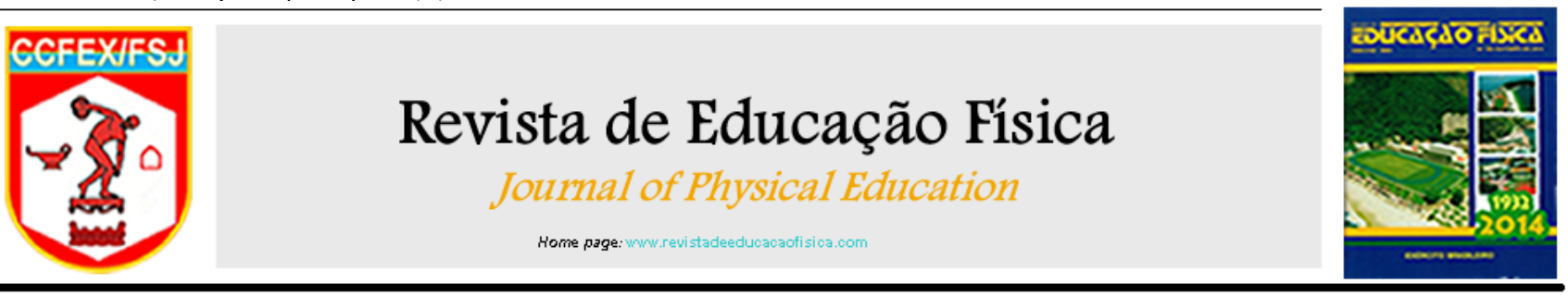

Resumo

\title{
Efeito agudo da pista de treinamento em circuito do Exército Brasileiro em marcadores cardiorrespiratórios
}

Fábio Leal Silva Bsci, Rafael Melo MSci

Introdução: A realização de pesquisas do efeito de treinamento resistido e treinamento de resistência em circuito na aptidão cardiorrespiratória é evidente, porém existe uma deficiência de estudos sobre o efeito agudo da pista de treinamento em circuito do Exército Brasileiro nos diferentes períodos de execução previsto no C 20-20.

Objetivo: Verificar a influência da pista de treinamento em circuito do Exército Brasileiro nos diferentes períodos de tempo em marcadores cardiorrespiratórios.

Métodos: A amostra foi composta por oito voluntários do sexo masculino, a idade média de $27( \pm 2,67)$ anos, peso médio $77( \pm 11,55) \mathrm{kg}$, estatura média $1,75( \pm 0,05) \mathrm{m}$, alunos da Escola de Educação Física do Exército. Os participantes, utilizando o frequencímetro cardíaco, fizeram o fitness teste para predição indireta do $\mathrm{VO}_{2}$ máximo, mensuração da frequência cardíaca de repouso e da frequência cardíaca máxima. Após o teste foi realizado as passagens na pista de treinamento em circuito com no mínimo 48 horas de intervalo. Foram executadas três passagens, sendo a primeira foi a 30 segundos, a segunda, a 45 segundos e a terceira a 60 segundos. Os principais marcadores cardiorrespiratórios coletados foram a frequência cardíaca inicial, frequência cardíaca de esforço máxima, frequência cardíaca de esforço média, gasto calórico médio no esforço. Foi empregado o teste de ANOVA para comparação entre as variáveis em estudo.

Resultados: Não houve diferença significante na frequência cardíaca de esforço máxima e da frequência cardíaca de esforço média, contudo, indicou haver diferença no gasto calórico médio de esforço e na variação da frequência cardíaca de esforço máxima e inicial.

Conclusão: Não houve efeito da passagem na pista de treinamento em circuito do Exército Brasileiro nos períodos de tempo de 30 e 45 segundos em marcadores cardiorrespiratórios. Dessa maneira, pode ser desconsiderada uma das passagens. 